\title{
AN ANNOTATED CHECKLIST OF FISHES FROM BHUTAN
}

\author{
Dhan Bahadur Gurung ${ }^{1}$, Sangay Dorji ${ }^{2}$, Ugyen Tshering ${ }^{3} \&$ Jigme T. Wangyal ${ }^{4}$ \\ ${ }^{1}$ College of Natural Resources, Royal University of Bhutan, Punakha, Lobesa, Bhutan \\ ${ }^{2}$ Royal Manas National Park, Gelephu, Sarpang, Bhutan \\ ${ }^{3}$ Dzongkhag Forestry, Thimphu, Bhutan \\ ${ }^{4}$ District Forest Office, District Administration, Trashigang 42001, Bhutan \\ ${ }^{1}$ dbg2006@gmail.com (corresponding author), 2 sangaydorji73@gmail.com, ${ }^{3}$ ugyen_00@yahoo.com, \\ 4 jigmewangyal@gmail.com
}

Abstract: We examined 66 species of fishes during an ichthyofaunal diversity survey of Bhutan in 2011 and provide an annotated checklist of the freshwater fish species known to occur in Bhutan. A total of 91 species are now known from Bhutan, but this is clearly a gross underestimate of the true freshwater fish diversity of the country. This highlights the need for more extensive freshwater fish surveys to be carried out in the country.

Keywords: Bhutan, diversity, fishes.

The first record of freshwater fish from Bhutan was by McClelland (1839) who reported Balitora brucei Gray and Schizothorax richardsonii Gray from the 1835 Boutan (sic) expedition of William Griffith. Five fish species were subsequently recorded from Bhutan by Day (1889) as part of a larger work on the fishes of South Asia. The most comprehensive listings of the freshwater fishes of Bhutan till date by Dubey (1978), Dhendup \& Boyd (1994), and Petr (1999) record 47 species, of which eight are alien. In a study of the fish diversity in the Bumdeling Wildlife Sanctuary, Bhattarai \& Thinley (2005) recorded 52 species; with Dema (2007) adding Triplophysa stoliczkai (Steindachner) to the list of fish species found in Bhutan.

In comparison to the 520 species reported from the eastern Himalayan region (Allen et al. 2010), 213 from the Arunachal Pradesh in northeastern India (Bagra et al. 2009), and 296 species from northeastern India (Vishwanath et al. 2007) the number of fish species currently known from Bhutan is a gross underestimate. The paucity of information on the fish fauna of Bhutan is mainly attributed to the very poor representation of material in collections and the conservation regulations that prohibit fishing without a permit, making collection of fresh material difficult.

The major drainage systems of Bhutan from the east to west are the Dangmechhu and Mangdechhu (Manas), Punatsangchhu (Sankosh), Wangchhu (Raidak) and Amochhu (Toorsa), with all these rivers debouching into the Brahmaputra River in India. In the higher elevations, these rivers support very low fish diversity due to their low productivity (Dubey 1978). There are also lakes in Bhutan, with Brown Trout (Salmo trutta fario Linnaeus) introduced in high altitude lakes (e.g., Nobtshonapata located at 4092m in Haa District and Tshophu at $4405 \mathrm{~m}$ in Paro District) and Common Carp (Cyprinus carpio Linnaeus) in the lower altitude lakes (e.g., Hokotsho in Punakha and Ada in Wangduephodrang).

Given our poor knowledge of Bhutanese ichthyofaunal diversity and the imminent threats to aquatic biodiversity arising from large hydropower

DOI: http://dx.doi.org/10.11609/JoTT.o3160.4880-6 | ZooBank: urn:Isid:zoobank.org:pub:375212FC-3281-4EOD-B0ED-OA8F980E807A

Editor: Heok Hee Ng, National University of Singapore, Singapore.

Date of publication: 26 October 2013 (online \& print)

Manuscript details: Ms \# 03160 | Received 13 April 2012 | Final received 02 October 2013 | Finally accepted 04 October 2013

Citation: Gurung, D.B., S. Dorji, U. Tshering \& J.T. Wangyal (2013). An annotated checklist of fishes from Bhutan. Journal of Threatened Taxa 5(14): 4880-4886; http://dx.doi.org/10.11609/JoTT.03160.4880-6

Copyright: @ Gurung et al. 2013. Creative Commons Attribution 3.0 Unported License. JoTT allows unrestricted use of this article in any medium, reproduction and distribution by providing adequate credit to the authors and the source of publication.

Funding: Rufford Small Grant Foundation.

Competing Interest: Authors declare no competing interests.

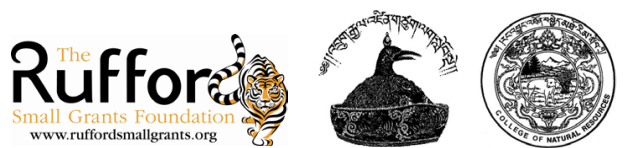

Acknowledgements: The authors are grateful to the Rufford Small Grant Foundation and the Royal University of Bhutan for providing financial support for the study. We acknowledge all the forestry staff who provided assistance during the ichthyofaunal survey. 
projects planned in all the major rivers of Bhutan, an assessment of freshwater fish diversity in Bhutan is not only timely, but also necessary. In this study, based on a rapid assessment of ichthyofaunal diversity in selected water bodies of Bhutan, we present a list of 91 fishes that are now known to occur in Bhutan.

\section{Materials and Methods}

We divided a topographical map of Bhutan into different grids and used convenience sampling to assess the ichthyofaunal diversity in each grid. Focus was given to subtropical (below $1000 \mathrm{~m}$ ) rivers under the assumption that the diversity is higher in warmer water bodies (Fig. 1). Sampling was carried out in both the monsoon and post-monsoon seasons to cover both migratory and residential species. We sampled with cast nets wherever possible, and conducted searches by hand for species with cryptic behaviour. Basic parameters of water like $\mathrm{pH}$, dissolved oxygen, and temperature were recorded at the sampling sites. Geographical coordinates and altitudes were also recorded.

Morphometric data were measured to a tenth of a millimetre using a dial calliper. We used existing literature (Day 1889; Jayaram 1999; Ng 2006; Vishwanath et al. 2007; Ng \& Kottelat 2008; Jayaram 2009; Fishbase 2012; Nebeshwar et al. 2012) to identify the species and sought experts' advice wherever possible. For uncertain species, voucher specimens were prepared after euthanizing the fishes with $0.0001 \%$ clove oil solution and treating in 10\% formalin (Li \& Li 2007). After 1-2 weeks of fixation in formalin, the specimens were transferred to $70 \%$ alcohol. The specimens were catalogued and preserved as voucher specimens in the laboratory collection of the College of Natural Resources (CNR).

\section{Results and Discussion}

We collected and examined 66 species of fishes from different regions of Bhutan. In order to avoid repeated collections and support scientific studies in future, 135 specimens comprising 45 species were catalogued and preserved as voucher specimens. For small species that could not be tagged easily, digital photographs were taken and preserved without catalogue numbers. Here, we provide a list of 91 fish species confirmed as occurring in Bhutan. However, species from Dubey

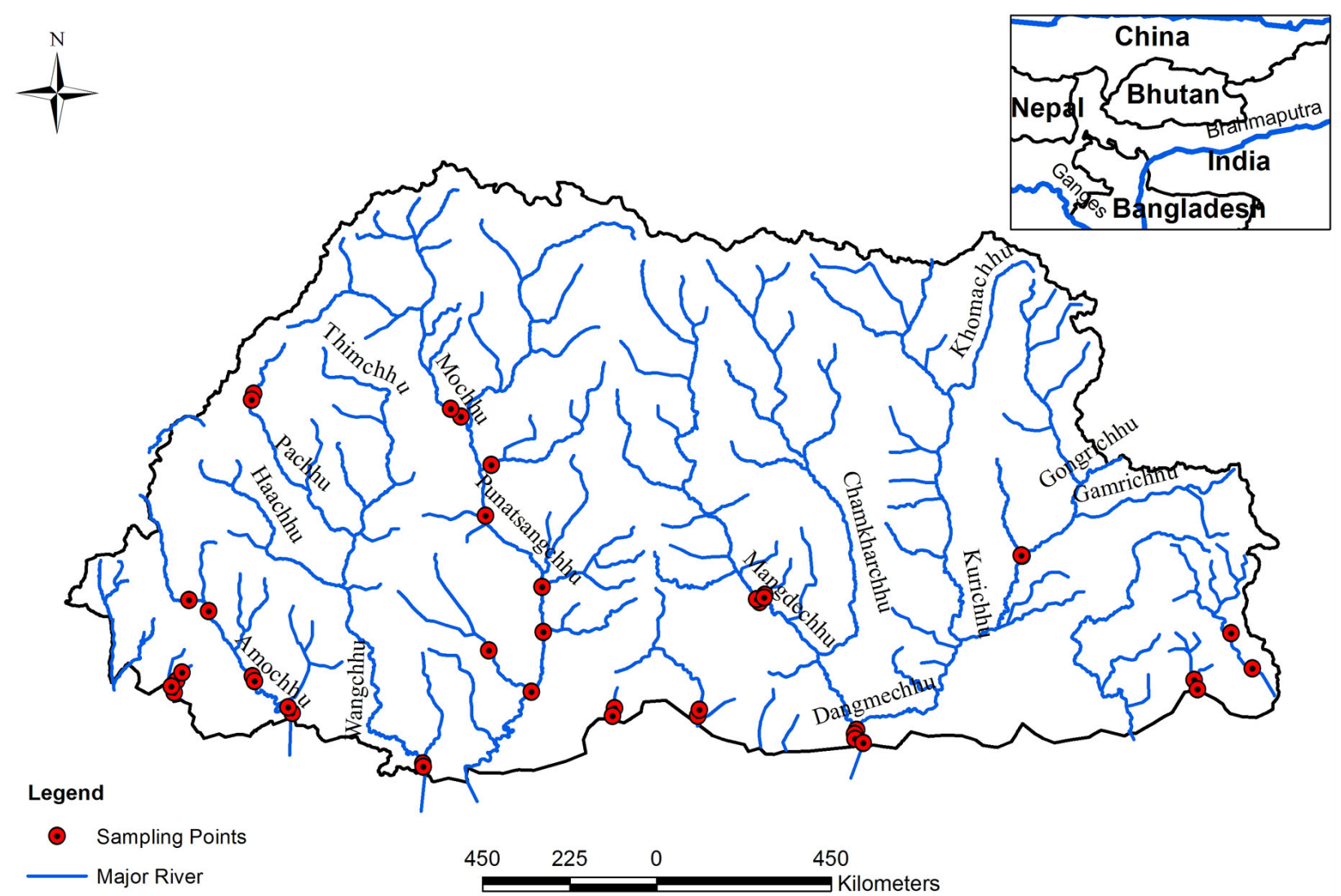

Figure 1. Map of study area 
(1978), Dhendup \& Boyd (1994), Petr (1999), and Bhattarai \& Thinley (2005) included here and for which we have not seen material requires reinvestigation to verify their identities.

\section{Annotated checklist}

\section{Order Anguilliformes}

Family: Anguillidae

1. Anguilla bengalensis (Gray, 1831) (Image 1). Locality: Nyera-amachhu in Samdrup Jongkhar, Manas in Panbang (Zhemgang), Maokhola in Sarpang and Dhamdum in Samtse.

\section{Order Cypriniformes}

Family: Cyprinidae

2. Hypophthalmichthys molitrix (Valenciennes, 1844). Locality: Introduced in Sarpang and Samdrup Jongkhar.

3. Hypophthalmichthys nobilis (Richardson, 1885). Locality: Introduced in Sarpang and Samdrup Jongkhar.

4. Aspidoparia morar (Hamilton, 1822) (CNR 11118 \& CNR 11053). Locality: Diglai in Samdrup Jongkhar and Manas in Panbang (Zhemgang).

5. Barilius barna (Hamilton, 1822) (CNR 11112 \& CNR 11115). Diglai in Samdrup Jongkhar.

6. Barilius bendelisis (Hamilton, 1807) (CNR 11013). Locality: Manas in Panbang (Zhemgang).

7. Barilius vagra (Hamilton, 1822) (CNR 11045 \& CNR 11138). Locality: Serichhu in Salamji (Dagana) and Manas in Panpang (Zhemgang).

8. Raiamas bola (Hamilton, 1822) (CNR 11032). Locality: Manas in Panbang (Zhemgang).

9. Danio dangila (Hamilton, 1822) (CNR 11136). Locality: Manas in Panbang (Zhemgang).

10. Danio rerio (Hamilton, 1822). Reported by Dubey (1978), Dhendup \& Boyd (1994), Petr (1999), and Bhattarai \& Thinley (2005), so no material was examined.

11. Devario aequipinnatus (McClelland, 1839) (CNR 11182). Locality: Maokhola in Sarpang.

12. Rasbora daniconius (Hamilton, 1822). Reported by Dubey (1978), Dhendup \& Boyd (1994), Petr (1999), and Bhattarai \& Thinley (2005), so no material was examined.

13. Ctenopharyngodon idella (Valenciennes, 1844). Locality: Introduced for aquaculture in Sarpang and Samdrup Jongkhar.

14. Cyprinus carpio Linnaeus, 1758. Locality: Introduced for aquaculture in Sarpang and Samdrup Jongkhar.

15. Tor putitora (Hamilton, 1822) (CNR 11179 \& CNR 11049). Locality: Diglai in Samdrup Jongkhar and

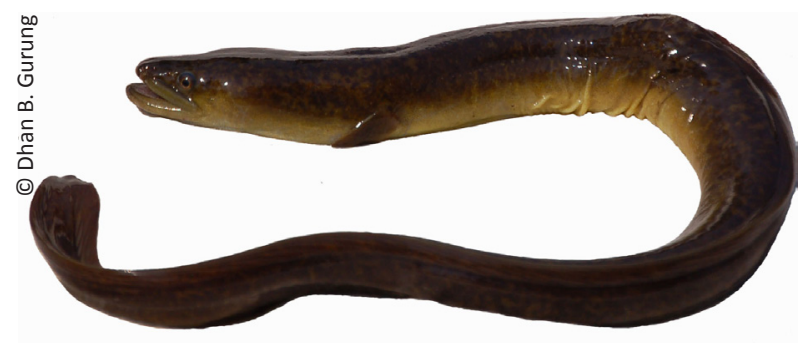

Image 1. Anguilla bengalensis

Kalikhola in Sarpang.

16. Tor tor (Hamilton, 1822). Reported by Dubey (1978), Dhendup \& Boyd (1994), Petr (1999), and Bhattarai \& Thinley (2005), so no material was examined.

17. Neolissochilus hexagonolepis (McClelland, 1839) (CNR 10002, CNR 11036 \& CNR 11180). Locality: Dhamdum in Samtse, Dikchhu in Wangdue Phodrang and Diglai in Samdrup Jongkhar.

18. Chagunius chagunio (Hamilton, 1822) (CNR 11150). Locality: Kalikhola in Sarpang.

19. Puntius chola (Hamilton, 1822). Reported by Dubey (1978), Dhendup \& Boyd (1994), Petr (1999), and Bhattarai \& Thinley (2005), so no material was examined.

20. Puntius sophore (Hamilton, 1822). Reported by Dubey (1978), Dhendup \& Boyd (1994), Petr (1999), and Bhattarai \& Thinley (2005), so no material was examined.

21. Puntius ticto (Hamilton, 1822). Reported by Dubey (1978), Dhendup \& Boyd (1994), Petr (1999), and Bhattarai \& Thinley (2005), so no material was examined.

22. Puntius sarana (Hamilton, 1822). Reported by Dubey (1978), Dhendup \& Boyd (1994), Petr (1999), and Bhattarai \& Thinley (2005), so no material was examined.

23. Semiplotus semiplotus (McClelland, 1839) (CNR 12120). Locality: Diglai in Samdrup Jongkhar.

24. Cirrhinus mrigala (Hamilton, 1822). CNR 00174. Locality: Introduced for aquaculture in Sarpang and Samdrup Jongkhar.

25. Catla catla (Hamilton, 1822). Locality: In aquaculture in Sarpang and Samdrup Jongkhar.

26. Labeo dyocheilus (McClelland, 1839) (CNR 12098). Locality: Diglai in Samdrup Jongkhar.

27. Labeo pangusia (Hamilton, 1822) (CNR 11058). Locality: Budichhu in Tsirang.

28. Labeo rohita (Hamilton, 1822). Locality: Introduced in Sarpang and Samdrup Jongkhar.

29. Bangana dero (Hamilton, 1822). Reported by Dubey (1978), Dhendup \& Boyd (1994), Petr (1999), and Bhattarai \& Thinley (2005), so no material was examined.

30. Schizothorax molesworthi (Chaudhury, 1913). Reported by Dubey (1978), Dhendup \& Boyd (1994), Petr 
(1999), and Bhattarai \& Thinley (2005), so no material was examined.

31. Schizothorax progastus (McClelland, 1839) (CNR 11016). Locality: Serichhu in Salamji (Dagana).

32. Schizothorax richardsonii (Gray, 1832) (CNR 11017-11023). Locality: Punatsangchhu in Punakha, Dikchhu in Wangdue Phodrang and Rangchoechhu in Gakiling ( $\mathrm{Ha}$ ).

33. Crossocheilus latius (Hamilton, 1822) (CNR 11001). Locality: Dagachhu in Dagana.

34. Garra annandalei Hora, 1921 (CNR 00173). Locality: Sarpang.

35. Garragotyla (Gray, 1830). Locality: Punatsangchhu in Wangdue Phodrang and Tsirang.

36. Garra sp. (CNR 11060 \& CNR 11061). Locality: Serichu at Salamji (Dagana).

Family: Psilorhynchidae

37. Psilorhynchus balitora (Hamilton, 1822) (CNR 11196, Image 2). Locality: Manas in Panbang (Zhemgang).

38. Psilorhynchus homaloptera Hora \& Mukerji, 1935 (CNR 11195). Locality: Dakpaichhu in Zhemgang.

Family: Balitoridae

39. Balitora brucei Gray, 1830. Reported by Dubey (1978), Dhendup \& Boyd (1994), Petr (1999), and Bhattarai \& Thinley (2005), so no material was examined.

40. Acanthocobitis botia (Hamilton, 1822) (CNR 00169). Locality: Manas in Panbang (Zhemgang).

41. Schistura inglisi Hora, 1935 (CNR 10188 \& 10189). Locality: Singhikhola in Puntsholing (Chukha).

42. Schistura multifasciata (Day, 1878). Reported by Dubey (1978), Dhendup \& Boyd (1994), Petr (1999), and Bhattarai \& Thinley (2005), so no material was examined.

43. Schistura cf. reticulofasciatus (Singh \& Banarescu, 1982) (CNR 12100, Image 3). Locality: Diglai in Samdrup Jongkhar.

44. Schistura scaturigina McClelland, 1839. Reported by Dubey (1978), Dhendup \& Boyd (1994), Petr (1999), and Bhattarai \& Thinley (2005), so no material was examined.

45. Schistura sp. (CNR 11197, Image 4). Locality: Manas in Panbang (Zhemgang).

46. Triplophysa stoliczkai (Steindachner, 1866) (CNR 12181). Locality: Headwaters of Pachhu in Jangothang (Paro) and Mochhu in Lingshi (Thimphu).

47. Aborichthys garoensis Hora, 1913 (CNR 12104). Locality: Diglai in Samdrup Jongkhar.

Family Cobitidae

48. Botia almorhae Gray, 1831 (CNR 10063). Locality:

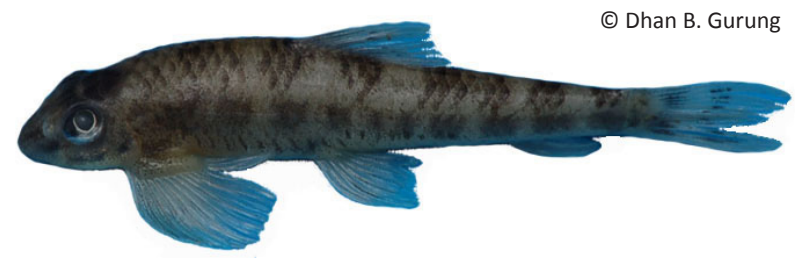

Image 2. Psilorhynchus balitora

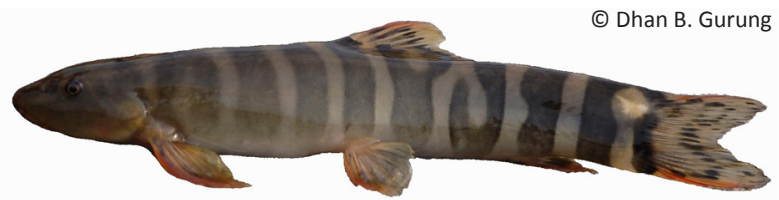

Image 3. Schistura cf. reticulofasciatus

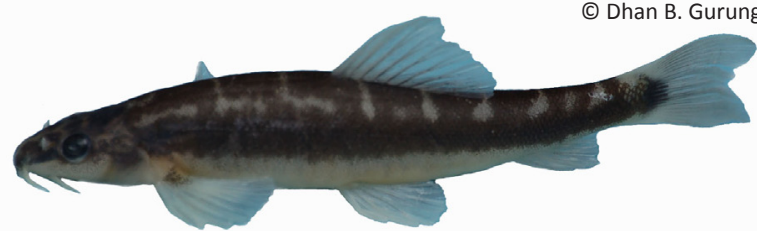

Image 4. Schistura sp.

Dagachhu in Dagana.

49. Botia dario (Hamilton, 1822). Reported by Dubey (1978), Dhendup \& Boyd (1994), Petr (1999), and Bhattarai \& Thinley (2005), so no material was examined.

50. Lepidocephalichthys guntea (Hamilton, 1822) (CNR 11140). Locality: Manas in Panbang (Zhemgang).

\section{Order Siluriformes}

Family: Bagridae

51. Mystus bleekeri (Day, 1877). Reported by Dubey (1978), Dhendup \& Boyd (1994), Petr (1999), and Bhattarai \& Thinley (2005), so no material was examined.

52. Mystus cf. dibrugarensis (Choudhury, 1913) (CNR 11184). Manas in Panbang (Zhemgang).

53. Mystus vittatus (Bloch, 1794). Reported by Dubey (1978), Dhendup \& Boyd (1994), Petr (1999), and Bhattarai \& Thinley (2005), so no material was examined.

54. Batasio batasio (Hamilton, 1822). Reported by Dubey (1978), Dhendup \& Boyd (1994), Petr (1999), and Bhattarai \& Thinley (2005), so no material was examined.

55. Batasio fasciolatus Ng, 2006 (CNR 11052). Locality: Manas in Panbang (Zhemgang).

56. Batasio merianiensis (Choudhury, 1913) (CNR 11113 \& CNR 11114). Locality: Diglai in Samdrup Jongkhar. 
Family: Siluridae

57. Ompok pabda (Hamilton, 1822). Reported by Dubey (1978), Dhendup \& Boyd (1994), Petr (1999), and Bhattarai \& Thinley (2005), so no material was examined.

58. Pterocryptis cf. barakensis Peters, 1861 (CNR 10006). Locality: Dhamdum in Samtse.

Family: Schilbeidae

59. Ailia coila (Hamilton, 1822) (CNR 11047). Locality: Manas in Panbang (Zhemgang).

Family: Amblycipitidae

60. Amblyceps apangi Nath \& Dey, 1989 (CNR 11165). Locality: Diglai in Samdrup Jongkhar.

61. Amblyceps mangois (Hamilton, 1822) (CNR 11054). Locality: Diglai in Samdrup Jongkhar.

\section{Family: Sisoridae}

62. Gogangra viridescens (Hamilton, 1822). Reported by Dubey (1978), Dhendup \& Boyd (1994), Petr (1999), and Bhattarai \& Thinley (2005), so no material was examined.

63. Gagata cenia (Hamilton, 1822) (CNR 11135). Locality: Manas in Panbang (Zhemgang).

64. Bagarius bagarius (Hamilton, 1822). Locality: Nyera-amachhu in Samdrup Jongkhar and Manas in Panbang (Zhemgang). No materials were collected.

65. Glyptothorax cavia (Hamilton, 1822) (CNR 11006). Locality: Amochhu in Phuntsholing (Chukha).

66. Glyptothorax striatus (McClelland, 1842) (CNR 11005). Locality: Dhamdum in Samtse.

67. Glyptothorax sp. (CNR 11144, Image 5). Locality: Punatsangchhu in Wangdue Phodrang.

68. Glyptothorax cf. telchitta (Hamilton, 1822) (CNR 12129, Image 6). Locality: Diglai in Samdrup Jongkhar.

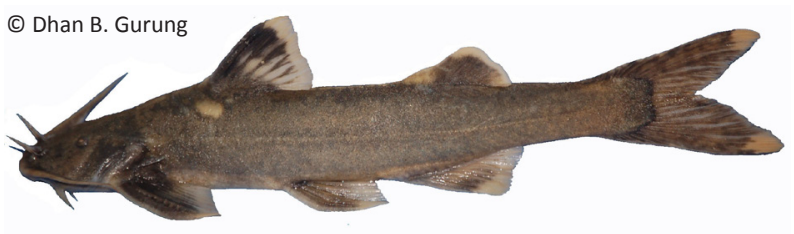

Image 5. Glyptothorax sp.

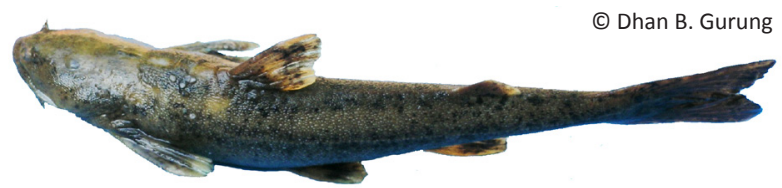

Image 6. Glyptothorax cf. telchitta
69. Exostoma labiatum (McClelland, 1842) (CNR

11011). Locality: Dakpaichhu in Zhemgang.

70. Parachiloglanis hodgarti (Hora, 1923) (CNR 11194). Locality: Dakpaichhu in Zhemgang.

71. Pseudecheneis sulcata (McClelland, 1842) (CNR 11010). Locality: Toeberongchhu in Punakha.

72. Pseudolaguvia ferula Ng, 2006 (CNR 11154). Locality: Kalikhola in Sarpang.

Family: Clariidae

73. Clarias gariepinus (Burchell, 1822). Locality: Sewerage tank and Toorsa in Phuntsholing (Chukha). No materials were collected.

74. Clarias magur (Hamilton, 1822) (CNR 00172). Locality: Sarpang.

Family: Heteropneustidae

75. Heteropneustes fossilis (Bloch, 1794). Locality: Amochhu in Phuntsholing (Chukha).

Family: Olyridae

76. Olyra cf. kempi McClelland, 1842 (CNR 11050). Locality: Manas in Panbang (Zhemgang).

\section{Order Salmoniformes}

Family: Salmonidae

77. Oncorhynchus mykiss (Walbaum, 1792). Locality: Introduced in cold water hatchery at Haa (Norbu 2013).

78. Salmo truta fario Linnaeus, 1758 (CNR 11178). Locality: Chamkharchhu in Bumthang.

Order Beloniformes

Family: Belonidae

79. Xenentodon cancila (Hamilton, 1822) (CNR 11048). Locality: Manas in Panbang (Zhemgang).

Order Synbranchiformes

Family: Mastacembelidae

80. Macrognathus morehensis Arunkumar \& Tombi, 2000 (CNR 11141). Locality: Manas in Panbang (Zhemgang).

81. Mastacembelus armatus (Lacepede, 1800) (CNR 00176). Locality: Sarpang.

\section{Order Perciformes}

Family: Nandidae

82. Badis badis (Hamilton, 1822) (CNR 11145). Locality: Manas in Panbang (Zhemgang).

83. Badis sp. (CNR 11162). Locality: Manas in Panbang (Zhemgang).

84. Nandus nandus (Hamilton, 1822). Reported by 
Dubey (1978), Dhendup \& Boyd (1994), Petr (1999), and Bhattarai \& Thinley (2005), so no material was examined.

Family: Cichlidae

85. Oreochromis mossambica (Peters, 1852) (CNR 10166). Locality: Crocodile farm in Phuntsholing (Chukha).

\section{Family: Channidae}

86. Channa amphibeus (McClelland, 1845). Reported by Dubey (1978), Dhendup \& Boyd (1994), Petr (1999), and Bhattarai \& Thinley (2005), so no material was examined.

87. Channa gachua (Hamilton, 1822) (CNR 00170). Locality: Sarpang.

88. Channa punctata (Bloch, 1793) (CNR 10177. Locality: Crocodile farm in Phuntsholing (Chukha).

89. Channa striata (Bloch, 1793). Reported by Dubey (1978), Dhendup \& Boyd (1994), Petr (1999), and Bhattarai \& Thinley (2005), so no material was examined.

90. Channa stewartii Bloch \& Schneider, 1801 (CNR 11168). Locality: Singhikhola in Phuntsholing (Chukha).

\section{Order Tetraodontiformes}

Family: Tetraodontidae

91. Tetraodon cutcutia Hamilton, 1822. Locality: Manas in Panbang (Zhemgang).

Although catfishes of the family Sisoridae were frequently recorded during the survey, they have not been reported in previous studies. While Glyptothorax striatus McClelland, G. cf. telchitta Hamilton, Exostoma labiatum McClelland, and Parachiloglanis hodgarti (Hora) are mostly found in the rivers of temperate Himalaya (between 1000 and 3000 m), G. cavia Hamilton was restricted to subtropical regions (below 1000m) only. Based on the illustrations provided, Glyptothorax reticulatum McClelland and Balitora brucei Gray reported by Bhattarai \& Thinley (2005) are reidentified here as Parachiloglanis hodgarti Hora and Psilorhynchus homaloptera Hora \& Mukherji respectively. From among the Siluridae, Pterocryptis cf. barakensis Vishwanath \& Sharma was found below $500 \mathrm{~m}$. Other catfishes like the Amblyceps apangi Nath and Dey, A. mangois Hamilton, and Olyra cf. kempi McClelland were also common in the subtropical (below $1000 \mathrm{~m}$ ) region.

We examined a specimen of Heteropneustes fossilis Bloch in a private aquarium at Phuntsholing that was reportedly collected from river Toorsa. Similarly, the only specimen of Channa punctata Bloch that we examined was collected from the crocodile farm at Phuntsholing.
Likewise, a juvenile specimen of Macrognathus morehensis Arunkumar \& Tombi was collected from River Manas during the monsoon.

The description of Garra species from the region (Viswanath et al. 2007; Nebeshwar et al. 2012) are inadequate for the diagnosis of Garra species found in Bhutan. Similarly, the taxonomic keys provided by Viswanath et al. (2007) and Jayaram (2009) are inadequate in resolving the taxonomy of the catfishes known from Bhutan.

Some non-native species were recorded during the survey. Onchorhynchus mykiss Walbaum was introduced in a hatchery at Haa in 2007 (Norbu 2013). It has not been released in the rivers of Bhutan yet, but its escape in the river nearby is suspected. Oreochromis mossambica Peters was collected from the crocodile farm at Phuntsholing; this species was probably introduced to Bhutan in the mid 1990s (Ram Bahadur, pers. comm.).

Clarias gariepinus (Burchell) is another introduced species found in a sewage system and river Toorsa at Phuntsholing. It was introduced through "tshethar" practice (a compassionate act of releasing live fish in river water to prevent killings, mostly practiced by Buddhist monks). Even the elderly people with religious inclination, other than the monks, buy live fishes from across the border town and release them in the river nearby. This method of introducing alien aquatic organisms has also been reported elsewhere ( $\mathrm{Ng} \&$ Tan 2010). The live fishes sold in the border towns of India adjoining Bhutan for such practices are imported from Bangladesh via Kolkata. Unless the people are educated on the ecological consequences of such practices, this may serve as a major avenue of the introduction of alien species into the freshwaters of Bhutan and will become a major threat to conservation of native species in the country.

\section{Conclusion}

This study records 91 fish species from Bhutan. As the survey was carried out mainly in the monsoon season, a more extensive sampling regime both temporally (covering the inter-monsoon period) and geographically (in other areas of the country not sampled during this survey) is necessary to gain a better understanding of the freshwater fish diversity of Bhutan.

Although Bhutan pursues conservation of native fish species fervently, this is hampered by the poor state of knowledge of the diversity. Compared to the number of species reported from adjoining areas, the list of species presented here is clearly a gross underestimate 
of the freshwater fish diversity of Bhutan. The rapid development sweeping over Bhutan and the planned mega-hydropower projects to harness $10,000 \mathrm{MW}$ by the year 2020 (RGOB 2010) is expected to have a significant impact on the biodiversity of the country, making it imperative that a further understanding of Bhutan's ichthyofaunal diversity is critically needed.

\section{REFERENCES}

Allen, D.J., S. Molur \& B.A. Daniel (Compilers) (2010). The Status and Distribution of Freshwater Biodiversity in the Eastern Himalaya. Cambridge, UK and IUCN, Gland, Switzerland and Zoo Outreach Organisation, Coimbatore, India, viii+88pp.

Bagra, K., K. Kadu, K. Nabeshwar-Sharma, B.A. Laskar, U.K. Sarkar \& D.N. Das (2009). Ichthyological survey and review of the checklist of fish fauna of Arunachal Pradesh, India. Check List 5(2): 330-350.

Bhattarai, S. \& P. Thinley (2005). Survey of fish fauna along with basic water quality in some rivers of Bumdeling Wildlife Sanctuary in eastern Bhutan. Thimphu, 15pp.

Day, F. (1889). The Fauna of British India, Including Ceylon and Burma. Taylor and Francis, London, 548pp.

Dema, K. (2007). New Fish Species Discovered in Lingshi. Kuensel, Kuensel Corporation, Thimphu.

Dubey, G.P. (1978). Survey of the waters of Bhutan physiography and fishery potential. Document Repository. FAO, Rome.

Fishbase (2012). List of Freshwater fishes for Bhutan. <http://fishbase. org>. Accessed on 15 May 2012.
Jayaram, K.C. (1999). The Freshwater Fishes of Indian Region. Narendra Publishing House, Delhi, 471pp.

Jayaram, K.C. (2009). Catfishes of India. Narendra Publishing House, Delhi, 383pp.

Li, H.W. \& J.L. Li (2007). Role of fish assemblages in stream communities, pp. 474-514. In: Hauer, F.R. \& G.A. Lamberti (eds.). Methods in Stream Ecology. Elsevier, London, 877pp.

McClelland, J. (1839). Indian Cyprinidae. Asiatic Researches (Bishop's College Press, Calcutta) 19: 217-471.

Nebeshwar, K., K. Bagra \& D.N. Das (2012). Garra kalpangi, a new cyprinid fish species Pisces: Teleostei) from upper Brahmaputra basin in Arunachal Pradesh, India. Journal of ThreatenedTaxa 4(2): 2353-2362; http://dx.doi.org/10.11609/JoTT.o1703.2353-62

$\mathrm{Ng}$, H.H. (2006). Pseudolaguvia ferula, a new species of sisoroid catfish (Teleostei: Erethistidae) from India. Zootaxa 1229: 59-68.

Ng, H.H. \& M. Kottelat (2008). The identity of Clarias batrachus (Linnaeus, 1758), with the designation of a neotype (Teleostei: Clariidae). Zoological Journal of the Linnean Society 153(4): 725732; http://dx.doi.org/10.1111/j.1096-3642.2008.00391.x

Ng, H.H. \& H.H. Tan (2010). An annotated checklist of the non-native freshwater fish species in the reservoirs of Singapore. Cosmos 6(1): 95-116; http://dx.doi.org/10.1142/S0219607710000504

Norbu, P. (2013). Re'trouting Our Rivers. Kuensel, Kuensel Corporation, Thimphu.

Petr, T. (1999). Coldwater Fish and Fisheries in Bhutan. FAO Fisheries Technical Papers. FAO, Rome, 6-12pp.

RGOB (2010). Economic Development Policy of the Kingdom of Bhutan, 2010. Royal Government of Bhutan, Thimphu.

Vishwanath, W., W.S. Lakra \& U.K. Sarkar (2007). Fishes of North East India. National Bureau of Fish Genetic Resources, Lucknow, India, 264pp.

WAPCOS (2009). Punatsangchhu - II Hydro-electric Project (6X165 MW) Detailed Project Report. WAPCOS Limited, Gurgaon, 42-49pp. 